\title{
Stimulatory effect of Shoyu polysaccharides from soy sauce on the intestinal immune system
}

\author{
HIROAKI MATSUSHITA $^{1}$, MAKIO KOBAYASHI ${ }^{1}$, RYO-ICHI TSUKIYAMA $^{1}$, \\ MAYUMI FUJIMOTO ${ }^{2}$, MAKOTO SUZUKI ${ }^{2}$, KEISUKE TSUJI ${ }^{2}$ and KENJI YAMAMOTO ${ }^{3}$ \\ ${ }^{1}$ Research Laboratory, Higashimaru Shoyu Co. Ltd., Tatsuno, Hyogo 679-4167; \\ ${ }^{2}$ School of Human Science and Environment, University of Hyogo, Shinzaike-honcho, Himeji, Hyogo 670-0092; \\ ${ }^{3}$ Graduate School of Biostudies, Kyoto University, Sakyo-ku, Kyoto 606-8502, Japan
}

Received March 24, 2008; Accepted May 5, 2008

DOI: 10.3892/ijmm_00000015

\begin{abstract}
Soy sauce (Shoyu) is a traditional Japanese fermented seasoning and is available worldwide. We investigated the effect of Shoyu polysaccharides (SPS) prepared from soy sauce on the intestinal immune system of mice. SPS enhanced the production of immunoglobulin A (IgA) from Peyer's patch cells in vitro, and its oral administration to 7-week-old male BALB/c mice for 2 weeks at a dose of $1.5 \mathrm{mg}$ per day significantly $(\mathrm{p}<0.01)$ increased the concentration of $\operatorname{IgA}$ in the intestine as compared to control mice. Furthermore, experiments on the intestinal transport of SPS in vitro using the human intestinal epithelial cell line Caco-2 confirmed the permeation of uronic acid to be timedependent. In conclusion, SPS of soy sauce enhanced the production of IgA in vitro and in vivo, and the digested SPS might cross the enterocytic monolayer. Thus, soy sauce is a potentially promising food for enhancing host defenses.
\end{abstract}

\section{Introduction}

Soy sauce (Shoyu) is a traditional Japanese fermented seasoning available worldwide (1). In Japanese shoyu, soybeans and wheat are the two main raw materials used in almost the same quantity. Proteins of the raw materials are completely degraded into peptides and amino acids by microbial proteolytic enzymes after fermentation, and no allergens of the raw materials are present in soy sauce (2). In contrast, polysaccharides originating from the cell wall of soybeans are resistant to enzymatic hydrolysis. These polysaccharides are present in soy sauce even after fermentation and are termed shoyu polysaccharides (SPS) (3). Recently,

Correspondence to: Dr Makio Kobayashi, Research Laboratory, Higashimaru Shoyu Co. Ltd., 100-3 Tominaga, Tatsuno-cho, Tatsuno, Hyogo 679-4167, Japan

E-mail: mkobayashi@higashimaru.co.jp

Key words: immunoglobulin A, Peyer's patch, Caco-2, shoyu polysaccharides, soy sauce we reported that SPS exhibited potent anti-allergic effects (3), enhancing both macrophage and lymphocyte functions (4) and also iron absorption (5) in vitro and in vivo. Furthermore, oral supplementation of SPS was an effective intervention for patients with allergic rhinitis $(6,7)$ and enhanced iron absorption in healthy women (5) in two double-blind placebo-controlled clinical studies.

The intestinal mucosa is the first line of host defense. Orally administered antigens interact with the gut-associated lymphoid tissue (GALT), which is a well-developed immune network that is involved not only in protection of the host from pathogens but also in preventing unusual reactions to ingested proteins. This immune response is mainly a humoral immune response mediated by immunoglobulin A ( $\operatorname{IgA}$ )-producing cells and results in the secretion of IgA which constitutes almost $80 \%$ of all the antibodies produced in mucosalassociated tissue $(8,9)$. This antibody inhibits microbial adherence and also prevents the absorption of antigens into mucosal surfaces (10).

Antigen uptake occurs through a specialized system represented by the M cells overlying Peyer's patch (PP) (11). $\mathrm{PP}$ is the major site in the intestine for inducing an active immune response between macrophages and dendritic cells and $\mathrm{T}$ and $\mathrm{B}$ lymphocytes. The activation of the oral immune system is clearly associated with activation of T cells in PP. Recently, the oral administration of certain lactic acid bacteria $(12,13)$ and water-soluble dietary fibers such as glucomannan and pectin $(14,15)$ has also been reported to enhance the mucosal IgA response.

The human intestinal epithelial cell line Caco-2 has been known to exhibit characteristics of both the small and large intestines and to express several carrier-mediated transport processes for amino acids, sugars, dipeptides, bile acids and nucleosides (16-18). This cell line forms confluent monolayers having the functional properties of transporting epithelia and has been widely used for studying drug transport mechanisms $(19,20)$. Recently, we elucidated the biological activities of SPS after their oral administration (3-7), but the absorption characteristics of SPS are still unknown.

Therefore, in the present study, we examined the effect of SPS on the promotion of IgA production in PP cells and the intestinal transport of SPS using the Caco-2 human intestinal 
epithelial cell line in order to clarify the immunological function of SPS as a functional dietary component from soy sauce.

\section{Materials and methods}

Preparation of Shoyu polysaccharides. Soy sauce (Shoyu) was fermented by Higashimaru Shoyu Co., Ltd. (Tatsuno, Hyogo, Japan) as described previously (3). Shoyu polysaccharides (SPS) were prepared from the dialysate of soy sauce according to the method of Kikuchi and Sugimoto (21) as follows: $10 \mathrm{ml}$ of soy sauce in seamless cellulose tubing (small size 18 , pore size $25 \AA$, molecular weight cutoff 12,000; Wako Pure Chemical Industries Ltd., Osaka, Japan) was dialyzed overnight in water at $4^{\circ} \mathrm{C}$ and then freeze-dried.

Animals. Male BALB/c mice were obtained from Clea Japan, Inc. (Tokyo, Japan) and bred in our laboratories. They were housed, 5 per cage, and fed a basal diet, CE-2 (Clea Japan, Inc.) and water ad libitum, in an animal room under a $12 \mathrm{~h}$ light/dark cycle at a temperature of $24 \pm 1^{\circ} \mathrm{C}$ and a humidity of $60 \pm 5 \%$. After a week of acclimation, they were used for the experiment.

Preparation of Peyer's patch $(P P)$ cells. PP cells from male 8 -week-old mice were prepared as described by Lim et al (22). Mice were sacrificed by cervical dislocation, and the intestine from each mouse was carefully removed and trimmed free of PP cells. PP cells were placed in $5 \mathrm{ml}$ of RPMI-1640 medium (Gibco BRL, Life Technologies, Paisley, Scotland) in a plastic dish. After being gently dispersed using a 5-ml sterile syringe plunger, the cell suspensions were passed through a 150-mesh nylon sieve and centrifuged at $600 \mathrm{x} \mathrm{g}$ for $5 \mathrm{~min}$. The cell pellet obtained was washed with $10 \mathrm{ml}$ of RPMI-1640 medium and then resuspended in $2 \mathrm{ml}$ of RPMI1640 medium containing 10\% heat-inactivated fetal bovine serum (FBS, Gibco BRL), $100 \mathrm{U} / \mathrm{ml}$ of penicillin (Sigma Chemical Co., St. Louis, MO, USA) and $100 \mu \mathrm{g} / \mathrm{ml}$ of streptomycin (Sigma Chemical Co.) which was termed RPMI-10\% FBS. The viability of PP cells was $>98 \%$ as determined with the dye exclusion test using trypan blue (Gibco BRL). The cells were cultured at $1 \times 10^{6}$ cells $/ 100 \mu 1$ in 96-well culture plates (Nalge Nunc International, Roskilde, Denmark). Next, $100 \mu 1$ of the test sample dissolved in RPMI-10\% FBS was added to the cell suspension, and the mixture was incubated for $72 \mathrm{~h}$ in a humidified $5 \% \mathrm{CO}_{2}$ incubator (BNA-11, Tabai Espec Co., Osaka, Japan) at $37^{\circ} \mathrm{C}$. The culture supernatant was then harvested to evaluate IgA levels. Lipopolysaccharide (LPS) from Salmonella typhimurium (IL7261, Sigma Chemical Co.) was used as a $\mathrm{PP}$ activator.

Measurement of total $\operatorname{IgA}$. A sandwich ELISA was principally conducted using a modified version of the method of Williams et al (23). First, 96-well culture plates were coated with $100 \mu \mathrm{l}$ of goat anti-mouse $\operatorname{IgA}(\alpha$-chain-specific, $5 \mu \mathrm{g}$ / $\mathrm{ml}$, Southern Biotechnology Associates Inc., Birmingham, CA, USA) in $0.01 \mathrm{M}$ carbonate-bicarbonate buffer (Sigma Chemical Co.), $\mathrm{pH} 9.6$, for $1 \mathrm{~h}$ at $37^{\circ} \mathrm{C}$. Then, after three washes with TPBS [phosphate-buffered saline (PBS) containing $0.05 \%$ Tween-20], the plates were coated with $300 \mu \mathrm{l}$ of bovine serum albumin in PBS for $1 \mathrm{~h}$ at $37^{\circ} \mathrm{C}$ and washed again with TPBS three times. Next, $50 \mu 1$ of culture supernatant was added to each well, and the plates were incubated for $1 \mathrm{~h}$ at $37^{\circ} \mathrm{C}$. After the plates were washed as above, $100 \mu \mathrm{l}$ of horseradish peroxidase-conjugated goat anti-mouse $\operatorname{IgA}(\alpha$-chain-specific, $1 \mu \mathrm{g} / \mathrm{ml}$ ) was added to each well. The plates were incubated for $1 \mathrm{~h}$ at $37^{\circ} \mathrm{C}$ and washed again. Finally, $100 \mu 1$ of azino-bis (3-ethylbenzthiazoline-6sulforic acid) diammonium salt $(0.6 \mathrm{mg} / \mathrm{ml}$, Sigma Chemical Co.) in $0.2 \mathrm{M}$ citrate buffer containing $0.006 \%$ hydrogen peroxide $(\mathrm{pH} 4.0)$ was added. After incubation at room temperature for $30 \mathrm{~min}$, color development was halted by adding $100 \mu 1$ of $1.5 \%$ oxalic acid dihydrate (Wako Pure Chemical Industries Ltd.). The absorbance was measured with a microplate reader (Fluostar Galaxy; BMG Labtechnologies Pty. Ltd., Victoria, Australia) at $492 \mathrm{~nm}$. The results were expressed as micrograms of $\operatorname{IgA} /$ milliliter of supernatant, as calculated from a standard curve.

Feeding procedure. A total of 15 male BALB/c mice, 6 weeks old (weighing 20-23 g), were used for this experiment. After preliminary breeding for 4 days, the mice were divided into 3 groups of 5. Mice of the test group were fed ad libitum with a basal diet, CE-2, containing 0.01 or $0.05 \%$ (w/w) SPS for 2 weeks. It was estimated that the oral dose of SPS was approximately 0.3 or $1.5 \mathrm{mg}$ per day per mouse. The control group was fed with the basal diet only. Mice were sacrificed on day 14 , and the intestines were removed from each mouse.

Collection of intestinal fluid. The intestinal fluid was obtained at the end of the feeding period. The procedure for its collection was previously described by Lim et al (22) with modifications. The intestine was carefully removed between the stomach-duodenum junction and the ileum ascending-colon junction. The intestinal contents were washed out using $1 \mathrm{ml}$ of cold PBS ( $\mathrm{pH} 7.2)$ and centrifuged at 2,000 x g for 30 min. The supernatant was collected for determination of $\operatorname{IgA}$.

Measurement of the permeation of SPS through Caco-2 cell monolayers. The procedure used to measure the permeation of SPS through the Caco-2 cells was a modified version of that described by Hidalgo et al (20). The Caco-2 cells were obtained from the American Type Culture Collection (ATCC, Rockville, MD, USA), and were maintained in Dulbecco's modified Eagle's medium (DMEM, Gibco BRL) supplemented with $10 \%$ FBS, $1 \%$ non-essential amino acids (Gibco BRL), $100 \mathrm{U} / \mathrm{ml}$ penicillin and $100 \mu \mathrm{g} / \mathrm{ml}$ streptomycin (10\% FBSDMEM) in a humidified $5 \% \mathrm{CO}_{2}$ incubator at $37^{\circ} \mathrm{C}$. The Caco- 2 cells were seeded at a density of $1.25 \times 10^{6}$ cells $/ 0.2 \mathrm{ml} /$ well in a 6.5 -mm-diameter membrane $(0.4-\mathrm{mm}$ pore size, $24-$ well plate; Transwell, Corning, NY, USA). The cells were used at 21 days after seeding. Transepithelial resistance was measured using Millicell ERS (Millipore, Eschborn, Germany), and a value $>800 \mathrm{ohm} \mathrm{x} \mathrm{cm}{ }^{2}$ was considered sufficient to study permeability. After washing with preheated $10 \%$ FBSDMEM, $0.1 \mathrm{mg}$ of SPS dissolved in $200 \mu \mathrm{l}$ of $10 \%$ FBSDMEM was added to the apical chamber $(0.1 \mathrm{mg}$ of SPS/ well), and $700 \mu 1$ of $10 \%$ FBS-DMEM was added to the 


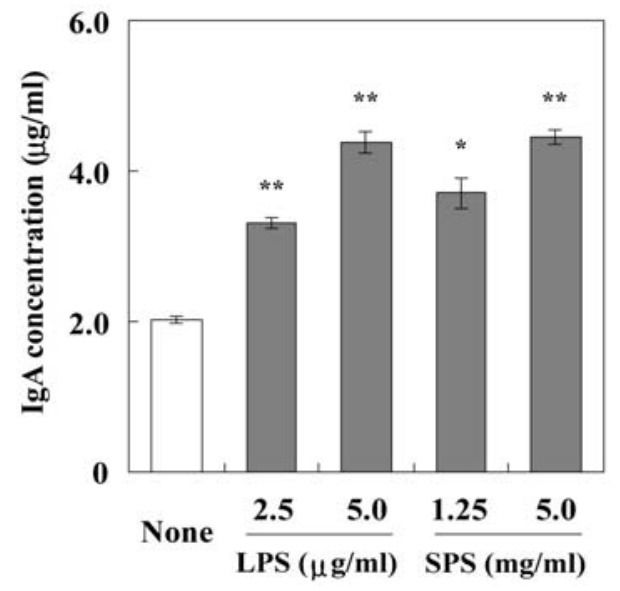

Figure 1. In vitro effect of SPS on IgA production in PP cells. For details concerning these experiments, see Materials and methods. LPS from the microbial cell wall was used as a positive control. The IgA concentrations in the culture supernatant were determined using the ELISA system. Each value is the average of triplicate cultures, and each bar indicates the mean \pm $\mathrm{SE}(\mathrm{n}=5)$. Significantly different from the control (none) at ${ }^{*} \mathrm{p}<0.05$ or ${ }^{* *} \mathrm{p}<0.01$ (Dunnett's test). LPS, lipopolysaccharide from Salmonella typhimurium.

basolateral chamber. The monolayers were incubated at $37^{\circ} \mathrm{C}$ for a period of 1,3 , or $6 \mathrm{~h}$. At each fixed time, the solution on the apical side was harvested to determine the permeability to SPS. Permeation rates of SPS were calculated based on the decreased amount of uronic acid.

Data analysis. Permeation rates were calculated according to the following equation: Permeation rate $(\%)=1-\mathrm{A} / \mathrm{B}$, where $\mathrm{A}$ is the uronic acid concentration in the apical chamber, and $\mathrm{B}$ is the initial uronic acid concentration in the chamber.

Assay of uronic acids. The procedure used to determine concentrations of uronic acids was a modification of that described by Blumenkrantz and Asboe-Hansen (24). To $0.2 \mathrm{ml}$ of the sample containing from 0.5 to $20 \mu \mathrm{g}$ of uronic acid, $1.2 \mathrm{ml}$ of sulfuric acid containing $0.0125 \mathrm{M}$ tetraborate was added. The mixture was heated in a water bath at $100^{\circ} \mathrm{C}$ for 5 min. After cooling in ice water, $20 \mu 1$ of $0.5 \% \mathrm{NaOH}$ containing $0.15 \%$ of $\mathrm{m}$-hydroxydiphenyl was added. The absorbance values were measured at $520 \mathrm{~nm}$. The uronic acid content was determined using galacturonic acid (Nacalai Tesque Inc., Kyoto, Japan) as a standard.

Statistical analysis. Statistical analysis was performed using the Dunnett's test. In all cases, a p-value $<0.05$ was considered to be statistically significant.

\section{Results}

Activation of PP cells by the addition of SPS. Fig. 1 shows the effect of SPS on the production of IgA by PP cells of mice. LPS of the microbial cell wall, which is known to activate PP cells and to produce $\operatorname{IgA}$, was used as a positive control sample in this experiment. According to the results, production increased significantly $(\mathrm{p}<0.05-0.01)$ upon the addition of SPS, as it did in response to LPS. The increase seemed to be dependent on the concentration of SPS.

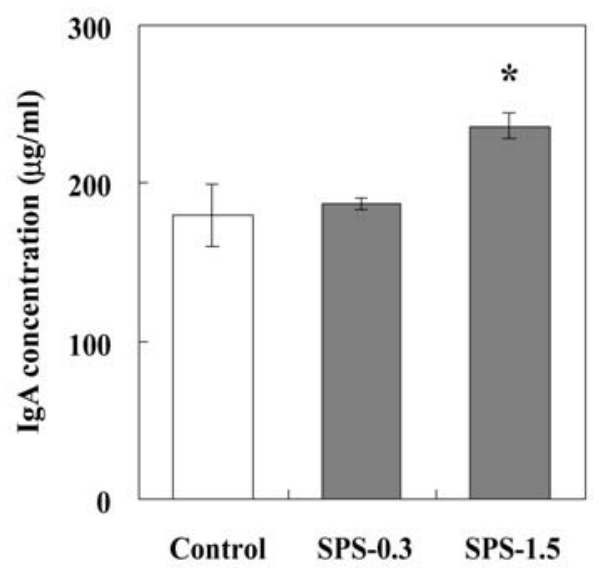

Figure 2. In vivo effect of SPS on production of intestinal secretary $\operatorname{IgA}$. For details concerning these experiments see Materials and methods. The oral dose of SPS was approximately 0.3 (SPS-0.3) or 1.5 (SPS-1.5) mg per day per mouse. The $\operatorname{IgA}$ concentration in the intestinal contents was determined using the ELISA system. Each value is the average of triplicate cultures, and each bar indicates the mean $\pm \operatorname{SE}(n=5)$. Significantly different from the control (none) at ${ }^{*} \mathrm{p}<0.01$ (Dunnett's test).

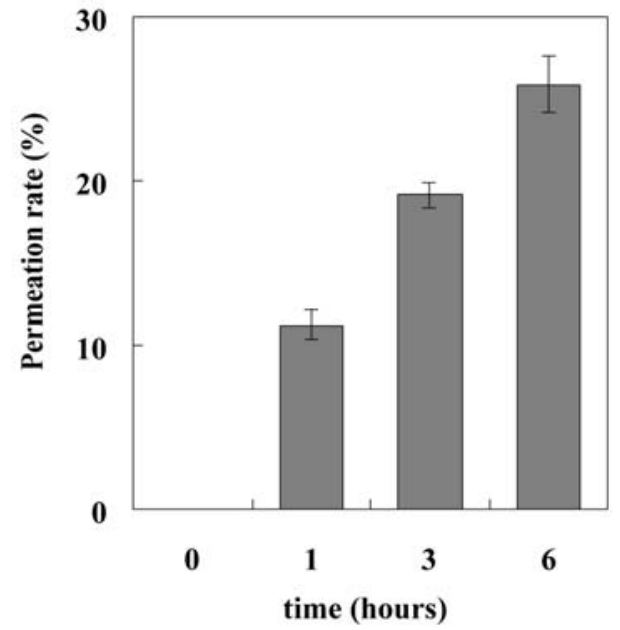

Figure 3. The permeability to SPS of Caco-2 cell monolayers. For details concerning these experiments, see Materials and methods. SPS was applied to the apical chamber. The samples were taken at 1,3, and $6 \mathrm{~h}$. At each fixed time, the solution on the apical side was harvested to determine permeability to SPS. Permeation rates were calculated according to the following equation: Permeation rate $(\%)=1-\mathrm{A} / \mathrm{B}$, where $\mathrm{A}$ is the uronic acid concentration in the apical chamber, and B is the initial uronic acid concentration in the chamber. Each bar indicates the mean $\pm \operatorname{SE}(n=4)$.

The effect of an oral dose of SPS on secretion of IgA in mouse intestines. The effect on the secretion of $\operatorname{IgA}$ in the intestines in mice fed SPS was estimated. The oral dose of SPS was approximately 0.3 or $1.5 \mathrm{mg}$ per day per mouse, as the animals ingested about $3 \mathrm{~g}$ of the diet per day per mouse throughout the feeding period. There were no significant differences in body weight among the groups (data not shown). As shown in Fig. 2, the production of IgA was significantly $(\mathrm{p}<0.01)$ greater in the SPS-1.5 group than in the control group.

The permeability to SPS of Caco-2 cell monolayers. Fig. 3 shows the time course of the apical to basolateral transport of 
SPS in Caco-2 cell monolayers. The amount of uronic acid moving across Caco-2 cell monolayers increased with time for up to $6 \mathrm{~h}$.

\section{Discussion}

The gastrointestinal tract is the most common site of entry for infectious agents at the mucosal surfaces. Secretory immunity is the basis for specific protection at the mucosal level, where $\operatorname{IgA}$ is the main immunoglobulin. Mucosal IgA prevents the adhesion of bacteria or viruses, and reduces the absorption of food antigens in the intestine (25-27). Yasui et al (28) reported that certain lactic acid bacteria which generate large quantities of IgA could prevent infections of the rotavirus. In the present study, we demonstrated that SPS of soy sauce enhanced IgA production in PP cells in vitro. In fact, compared to that of the control group of mice, the $\operatorname{Ig}$ A concentration in the intestine of the mice fed SPS was significantly higher. These results suggest that SPS enhances IgA production through stimulation of the intestinal immune system and that SPS could be expected to prevent allergic reactions by interfering with the absorption of allergens and microbial infections. We previously reported that SPS exhibit strong anti-allergic activities (3), and this effect was exerted through the Th1/Th2 balance (4). In short, the results obtained in this study, together with our previous findings, confirm that SPS effectively enhances not only the systemic immune system but also the mucosal one, and provide new insight into the physiological role of SPS.

Next, we evaluated the absorption of SPS to epithelial cells using a Caco-2 cell model. It has been reported that Caco-2 cells undergo spontaneous differentiation in culture and exhibit the characteristics of mature enterocytes by forming polarized monolayers with a brush border and functionally competent tight junctions (20). Caco-2 cells can serve as a screen since compounds with high permeability in this model are typically well absorbed in vivo (29). Using this model, we showed that SPS might be transported across cell monolayers. This finding confirmed that intestinal absorption of uronic acid occurred and digested SPS was distributed within the body.

In conclusion, we demonstrated that SPS effectively enhanced mucosal IgA production. The results obtained here may provide new insight into the immunomodulating functions of SPS. Thus, soy sauce is a potentially promising food for enhancing host defenses.

\section{Acknowledgements}

The authors are grateful to Mr. Yoshimichi Hiramitsu, Dr Jun Wada and Mr. Ryuji Yamamoto (all from Kyoto University) for the technical suggestions and discussions. The authors are also grateful to Dr Kohei Ushio (Research Laboratory, Higashimaru Shoyu Co. Ltd.) for the critical reading of the manuscript and for helpful advice. This work was supported in part by a subsidy from the Ministry of Agriculture, Forestry and Fisheries of Japan (Program for new technology development to activate agriculture, forestry, fisheries and food industry by cooperating industry, academia and the government).

\section{References}

1. Yokotsuka T: Soy sauce biochemistry. Adv Food Res 30: 195-329, 1986.

2. Kobayashi M, Hashimoto Y, Taniuchi S and Tanabe S: Degradation of wheat allergen in Japanese soy sauce. Int J Mol Med 13: 821-827, 2004.

3. Kobayashi M, Matsushita H, Yoshida K, Tsukiyama R, Sugimura $\mathrm{T}$ and Yamamoto $\mathrm{K}$ : In vitro and in vivo anti-allergic activity of soy sauce. Int J Mol Med 14: 879-884, 2004.

4. Matsushita H, Kobayashi M, Tsukiyama R and Yamamoto K: In vitro and in vivo immunomodulating activities of Shoyu polysaccharides from soy sauce. Int J Mol Med 17: 905-909, 2006.

5. Kobayashi M, Nagatani Y, Magishi N, Tokuriki N, Nakata Y, Tsukiyama R, Imai H, Suzuki M, Saito M and Tsuji K: Promotive effect of Shoyu polysaccharides from soy sauce on iron absorption in animals and humans. Int J Mol Med 18: 1159-1163, 2006.

6. Kobayashi M, Matsushita H, Shioya I, Nagai M, Tsukiyama R, Saito M, Sugita T, Sugimura T and Yamamoto K: Quality of life improvement with soy sauce ingredients, shoyu polysaccharides, in perennial allergic rhinitis: a double-blind placebocontrolled clinical study. Int J Mol Med 14: 885-889, 2004.

7. Kobayashi M, Matsushita H, Tsukiyama R, Saito M and Sugita T: Shoyu polysaccharides from soy sauce improve quality of life for patients with seasonal allergic rhinitis: a double-blind placebocontrolled clinical study. Int J Mol Med 15: 463-467, 2005.

8. Macpherson AJ, Gatto D, Sainsbury E, Harriman GR, Hengartner $\mathrm{H}$ and Zinkernagel RM: A primitive T cellindependent mechanism of intestinal mucosal IgA responses to commensal bacteria. Science 288: 2222-2226, 2000.

9. McGhee JR, Mestecky J, Dertzbaugh MT, Eldridge JH, Hirasawa $\mathrm{M}$ and Kiyono $\mathrm{H}$ : The mucosal immune system: from fundamental concepts to vaccine development. Vaccine 10: 75-88, 1992.

10. Lamm ME: Interaction of antigens and antibodies at mucosal surfaces. Annu Rev Microbiol 51: 311-340, 1997.

11. Kraehenbuhl JP and Neutra MR: Epithelial M cells: differentiation and function. Annu Rev Cell Dev Biol 16: 301-332, 2000.

12. Perdigon G, Vintini E, Alvarez S, Medina M and Medici M: Study of the possible mechanisms involved in the mucosal immune system activation by lactic acid bacteria. J Dairy Sci 82: 1108-1114, 1999.

13. Takahashi T, Nakagawa E, Nara T, Yajima T and Kuwata T: Effects of orally ingested Bifidobacterium longum on the mucosal $\operatorname{Ig}$ A response of mice to dietary antigens. Biosci Biotechnol Biochem 62: 10-15, 1998.

14. Yamada K, Tokunaga Y, Ikeda A, Ohkura K, Kaku-Ohkura S, Mamiya S, Lim BO and Tachibana H: Effect of dietary fiber on the lipid metabolism and immune function of aged SpragueDawley rats. Biosci Biotechnol Biochem 67: 429-433, 2003.

15. Lim BO, Lee SH, Park DK and Choue RW: Effect of dietary pectin on the production of immunoglobulins and cytokines by mesenteric lymph node lymphocytes in mouse colitis induced with dextran sulfate sodium. Biosci Biotechnol Biochem 67: 1706-1712, 2003.

16. Blais A, Bissonnette $\mathrm{P}$ and Berteloot A: Common characteristics for $\mathrm{Na}$-dependent sugar transport in Caco-2 cells and human fetal colon. J Membr Biol 99: 113-125, 1987.

17. Chen J, Zhu Y and Hu M: Mechanisms and kinetics of uptake and efflux of L-methionine in an intestinal epithelial model (Caco-2). J Nutr 124: 1907-1916, 1994.

18. Hidalgo IJ and Borchardt RT: Transport of bile acids in a human intestinal epithelial cell line, Caco-2. Biochem Biophys Acta 1035: 97-103, 1990.

19. Pinto M, Robine-Leon S, Appay MD, Kedinger M, Triadou N, Dussaulx E, Lacroix B, Simon-Assmann P, Haffen K, Fogh J and Zweibaum A: Enterocyte-like differentiation and polarization of the human colon carcinoma cell line Caco-2 in culture. Biol Cell 47: 323-330, 1983.

20. Hidalgo IJ, Raub TJ and Borchardt RT: Characterization of the human colon carcinoma cell line (Caco-2) as a model system for intestinal epithelial permeability. Gastroenterology 96: 736-749, 1989.

21. Kikuchi T and Sugimoto H: Detailed structure of an acidic polysaccharide in soy sauce, confirmed by use of two kinds of purified pectinases. Agric Biol Chem 40: 87-92, 1976.

22. Lim TS, Messiha N and Watson RR: Immune components of the intestinal mucosae of ageing and protein deficient mice. Immunology 43: 401-407, 1981. 
23. Williams DJL, Newson J and Naessens J: Quantitation of bovine immunoglobulin isotypes and allotypes using monoclonal antibodies. Vet Immunol Immunopathol 24: 267-283, 1990.

24. Blumenkrantz N and Asboe-Hansen G: New method for quantitative determination of uronic acids. Anal Biochem 54: 484-489, 1973.

25. Andre C, Lambert R, Bazin H and Heremans JF: Interference of oral immunization with the intestinal absorption of heterologous albumin. Eur J Immunol 4: 701-704, 1974.

26. Silbart LK and Keren DF: Reduction of intestinal carcinogen absorption by carcinogen-specific secretory immunity. Science 243: 1462-1464, 1989.
27. Stokes CR, Soothill JF and Turner MW: Immune exclusion is a function of IgA. Nature 255: 745-746, 1975.

28. Yasui H, Kiyoshima $\mathbf{J}$ and Ushijima H: Passive protection against rotavirus-induced diarrhea of mouse pups born to and nursed by dams fed Bifidobacterium brebe YIT4064. J Infect Dis 172: 403-409, 1995.

29. Balimane PV, Chong S and Morrison RA: Current methodologies used for evaluation of intestinal permeability and absorption. $\mathrm{J}$ Pharmacol Toxicol Methods 44: 301-312, 2000. 